\title{
ARTICLE OPEN Tooth extraction education at dental schools across Europe
}

\author{
Henk S Brand ${ }^{1,2}$, Carlijn CJ van der Cammen ${ }^{1,2}$, Sophie ME Roorda ${ }^{1,2}$ and Jacques A Baart ${ }^{3}$
}

\begin{abstract}
OBJECTIVES/AIMS: To explore students' opinion about theoretical and clinical training in tooth extraction at different European dental schools.

MATERIALS AND METHODS: An online questionnaire, containing 36 dichotomous, multiple choice and Likert scale rating questions, was distributed among students of 56 different dental schools. After excluding schools where $<20$ students responded, 656 questionnaires from 23 dental schools remained for statistical analysis.

RESULTS: Dental schools showed a wide variation in the initial practical teaching of tooth extraction, from years 2 to 6 . Several schools used a preclinical training model, and most students considered this useful. Some students considered their knowledge about forceps and elevators insufficient (6-60\%), as well as their preparation for complications (5-60\%). Students usually had received education in forceps and elevator techniques. Inclusion of (non)surgical removal of retained roots and surgical removal of third molars showed a wide variety between dental schools. Less than half of the students reported education in surgical removal of impacted teeth. Students from four of the 23 dental schools felt insufficiently prepared in tooth extraction (Likert scale $\leqslant 3$ ). CONCLUSION: There is a wide variation among European dental schools in teaching programs of tooth extraction and the rating of these programs by students.
\end{abstract}

BDJOpen (2015) 1, 15002; doi:10.1038/bdjopen.2015.2; published online 23 October 2015

\section{INTRODUCTION}

Tooth extractions are frequently performed in the general dental practice. Forceps exodontia of teeth is established as a basic clinical skill for dental graduates. During forceps exodontia, however, there is always the possibility of fracture of parts of the root and the necessity to start a surgical extraction. This means that graduating dentists must be competent in both surgical techniques. This is reflected in the current profile for the European dentist. ${ }^{1}$ Tooth extractions are mentioned in competences 6.53 and 6.54, which state that a dentist must be competent at 'performing uncomplicated extraction of erupted teeth' and 'performing surgery for the uncomplicated removal of fractured or retained roots and the removal of uncomplicated partially erupted teeth'.

Various studies in the UK have evaluated the perceptions of recently graduated dentists about their preparedness to perform extractions in the dental practice. Almost all respondents perceived that the teaching at their dental school had given them sufficient knowledge to undertake simple forceps exodontia, but confidence levels to perform surgical extractions were considerably lower. ${ }^{2-8}$ Similar results were observed for graduates of the dental school of the University of Hong Kong. Eighty-nine per cent of the students felt well prepared to perform simple extractions and $62 \%$ felt well prepared to extract impacted third molars. $^{9}$

Surveys among staff and students of dental schools across Europe have shown a considerable variation in dental curricula with regard to the teaching of local anaesthesia, tooth colour determination systems and fixed prosthodontics. ${ }^{10-13}$ This variation in teaching can influence the level of confidence of dental students, which may also apply when administering a tooth extraction in a patient. This suggestion is supported by the observation that students from the dental school in Cardiff in the UK were significantly more confident in performing simple extractions, as well as surgical extractions than students from the dental school in Cork in Ireland. ${ }^{6}$ Therefore, the aim of the present study was to explore the perception of students from different dental schools in Europe about their education in tooth extraction.

\section{MATERIALS AND METHODS}

This study is part of a series of studies performed by the Academic Centre of Dentistry Amsterdam, which explores the variation in curricula between dental schools across Europe. ${ }^{10-13}$ For the present study, an online questionnaire about the teaching of tooth extraction was developed. The first part of the questionnaire collected general information about dental school, gender and study year. In the second part, the extraction education of the student was explored with 36 dichotomous, multiple choice or rating scale questions. The opinion of the respondents about several aspects of the extraction education was rated with five-point Likert scales. A score of 1 meant 'absolutely not' or 'very bad' and a score of 5 did mean 'absolutely' or 'very good'. The total number of questions to be answered depended on the student's individual situation.

The questions were entered in the internet survey program eXamine 2.0. ${ }^{14}$ For the distribution of the questionnaire, the Deans of 145 dental schools who were member of the Association for Dental Education in Europe were approached. In addition, all delegates mentioned on the website of the European Dental Students Association were approached. A web link to the questionnaire was sent with an explanatory E-mail to the Deans and European Dental Students Association delegates, and they were asked to distribute the web link among all students of their dental school. The questionnaire was distributed in October and November 2011. The students were asked to answer the questionnaire within a period of 6 weeks. Participation was on a voluntary base, and all responses were anonymous.

\footnotetext{
1Department of Oral Biochemistry, Academic Centre for Dentistry Amsterdam (ACTA), Amsterdam, The Netherlands; ${ }^{2}$ Department of Medical-Dental Interaction, Academic Centre for Dentistry Amsterdam (ACTA), Amsterdam, The Netherlands and ${ }^{3}$ Department of Oral and Maxillofacial Surgery, VU University Medical Centre/Academic Centre for Dentistry Amsterdam (ACTA), Amsterdam, The Netherlands.

Correspondence: HS Brand (h.brand@acta.nl)

Received 6 July 2015; accepted 28 August 2015
} 
Table 1. General characteristics of the responding students from 23 different European dental schools with regard to gender, study year and the year in which the students received the initial theoretical and practical teaching in extraction of teeth

\begin{tabular}{|c|c|c|c|c|c|c|}
\hline Dental school & Country & Useful questionnaires $^{\mathrm{a}}$ & Male (\%) & Study year (mean) & \multicolumn{2}{|c|}{ Initial teaching in year } \\
\hline Amsterdam & The Netherlands & 53 & 47 & 4.8 & 4 & 6 \\
\hline Bordeaux & France & 49 & 41 & 5.2 & 3 & 4 \\
\hline Brest & France & 21 & 57 & 3.8 & 2 & 4 \\
\hline Cardiff & United Kingdom & 25 & 24 & 4.3 & 3 & 3 \\
\hline Kaunas & Lithuania & 53 & 23 & 4.1 & 3 & 4 \\
\hline Kosice & Slovenia & 21 & 43 & 4.8 & 2 & 4 \\
\hline Leeds & United Kingdom & 23 & 52 & 4.5 & 3 & 3 \\
\hline London & United Kingdom & 32 & 38 & 4.7 & 3 & 3 \\
\hline Msida & Malta & 12 & 50 & 4.3 & 3 & 4 \\
\hline Nantes & France & 23 & 57 & 4.3 & 3 & 3 \\
\hline Nijmegen & The Netherlands & 32 & 22 & 4.8 & 3 & 4 \\
\hline Toulouse & France & 27 & 56 & 5.2 & 3 & 4 \\
\hline Trieste & Italy & 25 & 44 & 4.4 & 3 & 3 \\
\hline Turku & Finland & 23 & 22 & 4.3 & 3 & 3 \\
\hline Ulm & Germany & 24 & 38 & 4.6 & 3 & 4 \\
\hline
\end{tabular}

${ }^{a}$ Questionnaires were considered useful when the respondent reported to have received education in tooth extraction and completed at least half of the questions. When 20 or more questionnaires from a dental school were returned or more than half of the students had returned the questionnaire the dental school was included in the analysis.

The total number of respondents was 1,294 from 56 different dental schools in Europe. Questionnaires were considered useful when the respondent reported to have received education in tooth extraction. Less than 20 students from dental schools in Aachen, Berlin, Heidelberg, Leipzig (Germany), Clermont, Lille, Lyon, Montpellier, Nancy, Nice, Paris, Reims, Strasbourg (France), Groningen (Netherlands), Bergen (Norway), Arkhangelsk, Chelyabinsk, Kazan, Kirov, Moscow, Omsk, Samara, St Petersburg, Ufa (Russia), Novi Sad (Serbia), Ankara, Istanbul (Turkey), Bristol (UK) and Stockholm (Sweden) returned useful questionnaires. These numbers were considered too small to be representative and these dental schools were excluded from the statistical analysis. An exception was made for the very small dental school in Msida (Malta), where more than half of the students who had received education in tooth extraction returned the questionnaire. This resulted in 656 useful questionnaires from 23 different dental schools remaining for analysis (Table 1).

Data are expressed as percentages or mean \pm s.d. The rating scale items were statistically analysed using IBM SPSS Statistics version 21.0 (IBM Crop, Armonk, NY, USA). For overall analysis, the Kruskal-Wallis test was used followed by Mann-Whitney tests as post hoc procedure for pair-wise comparisons. Potential relations between parameters were explored with Spearman's rank order correlation coefficient. All levels of significance were set at $P<0.05$.

\section{RESULTS}

Table 1 presents general information about the respondents. In general, the percentage of male students is $<50 \%$, and usually they are in the fourth year of the study. The teaching of the theoretical aspects of tooth extraction usually starts in year 3, with Brest, Kosice and Plymouth starting 1 year earlier. The initial teaching of the practical aspects has a much wider variation in the dental curricula, and ranges from year 2 (Plymouth) to 6 (Amsterdam).

Table 2 gives an overview of the study material used during teaching of tooth extraction. Most dental schools use one or more textbooks (18-100\%) and handouts (9-96\%). Readers (0-73\%) and digital video discs or films (0-50\%) are less frequently used.
In general, students were quite satisfied with the provided material, with scores varying from 2.9 to 4.1 on a 5-point Likert scale.

The use of a preclinical training model before the first extraction in a human is frequently reported by students from Cardiff, Gent, Kosice, Leeds, Nantes, Plymouth and Turku (Table 3). The majority of the students who used a preclinical training model considered it a useful preparation for the subsequent tooth extraction in a patient. However, in Cardiff and Ghent, only small numbers of students found the preclinical training model useful $(27 \%$ and $36 \%$, respectively).

Students feel relatively well prepared in several areas related to perform a tooth extraction. Some students felt that their knowledge about forceps and elevators was insufficient (6-60\%), as well as their preparedness for complications (5-60\%). Only few students from all dental schools felt insufficiently prepared with regard to anatomy, prescription of analgesics, medication problems or legal aspects of tooth extraction.

Supervision during the first tooth extraction in a patient was mostly performed by a dentist or oral-maxillofacial surgeon (Table 4). In general, students were quite satisfied with the supervision, with scores varying from 3.6 to 4.8 .

There is a wide variation in specific extraction techniques included in the curricula of the surveyed dental schools (Table 5). A large majority of the students report that they have received education in forceps and elevator techniques $(42 \%-100 \%$ and $44 \%-100 \%$, respectively). For non-surgical and surgical removal of retained roots, as well as surgical removal of third molars, much larger differences between dental schools were observed $(5 \%-83 \%, 6 \%-71 \%$ and $0 \%-80 \%$, respectively). Only a minority of the students received education in surgical removal of impacted teeth $(0-50 \%)$. The widest variety in extraction techniques seems to be provided by the dental schools in Copenhagen, Nantes, Szeged and Plymouth. 
Table 2. Material used during teaching of tooth extraction at 23 different European dental schools and the opinion of the students about the material provided (range $1=$ absolutely not to $5=$ absolutely)

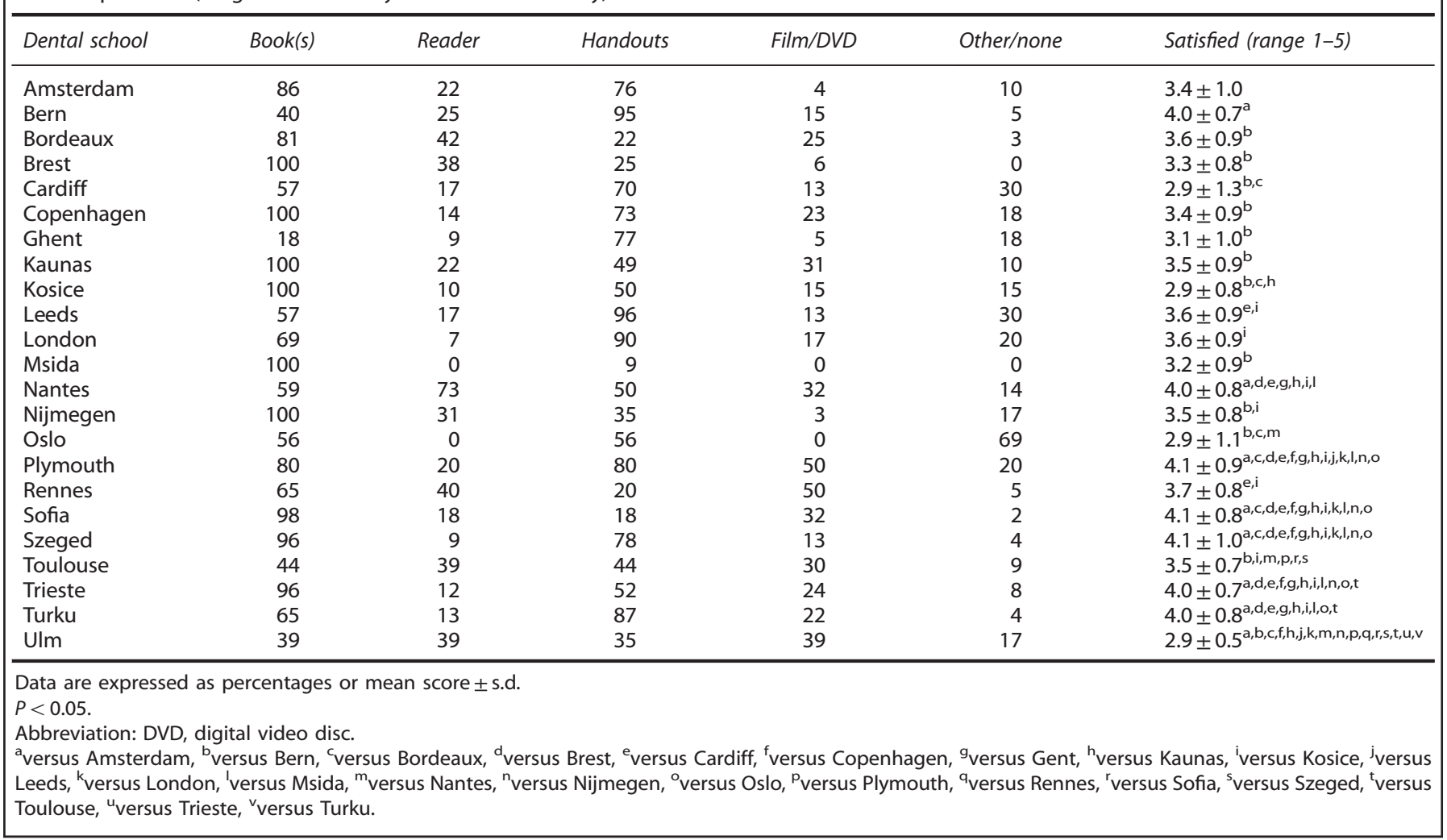

Table 3. The percentage of students from 23 different European dental schools reporting the use of a preclinical training model before their first tooth extraction in a human, and the opinion of the students who used such a model whether it was a useful preparation for the first extraction in a patient

\begin{tabular}{lcc}
\hline Dental school & Use of training model & Useful preparation \\
\hline Amsterdam & 4 & 0 \\
Bern & 5 & 100 \\
Bordeaux & 21 & 83 \\
Brest & 0 & - \\
Cardiff & 68 & 27 \\
Copenhagen & 5 & 100 \\
Ghent & 60 & 36 \\
Kaunas & 10 & 100 \\
Kosice & 67 & 75 \\
Leeds & 68 & 80 \\
London & 7 & 100 \\
Msida & 0 & - \\
Nantes & 50 & 100 \\
Nijmegen & 42 & 70 \\
Oslo & 17 & 50 \\
Plymouth & 95 & 90 \\
Rennes & 5 & 100 \\
Sofia & 52 & 89 \\
Szeged & 44 & 90 \\
Toulouse & 21 & 75 \\
Trieste & 4 & 100 \\
Turku & 82 & 67 \\
Ulm & 100 & 77 \\
\hline Data are expressed as percentages. & \\
\hline
\end{tabular}

Finally, Table 6 shows that students of dental schools across Europe vary considerable in their opinion whether they are properly trained in tooth extraction. Students from the dental school in Plymouth felt best prepared, closely followed by students from the dental schools in Szeged, Copenhagen, Trieste, Nantes and Sofia (all mean scores $\geqslant 4$ ). The students from 4 of the 23 surveyed dental schools felt insufficiently trained in tooth extraction (mean scores $\leqslant 3$ ). Students from the dental school in Szeged rated their training the highest (4.5), closely followed by students from the dental schools in Sofia and Plymouth. Students from 5 of the 23 surveyed dental schools were not very satisfied with the education in tooth extraction (mean scores $\leqslant 3$ ). The mean opinion of students about the education at their dental school correlated significantly with the year in the curriculum of the initial teaching of the practical aspects of tooth extraction $(r=-0.629, P=0.001)$. For the initial theoretical teaching, this relation with the overall satisfaction did not reach significance $(r=-0.388, P=0.067)$.

\section{DISCUSSION}

The present study of dental students' perceptions showed considerable variation among European dental schools in the teaching of tooth extraction and the rating of this teaching by students. This is in line with a previous study in the UK, showing variations between dental schools in content and delivery of the oral surgery clinical teaching programs. ${ }^{15}$ The undergraduate teaching of wisdom tooth removal in the UK showed also variation in the stage of the curriculum where this topic is taught. ${ }^{16}$

The initial teaching of the practical aspects of tooth extraction varies considerable between European dental schools with regard 
Table 4. Supervision of students from 23 different European dental schools during their first tooth extraction, the background of the supervisor and the opinion of the students about the supervision (range $1=$ absolutely not to $5=$ absolutely)

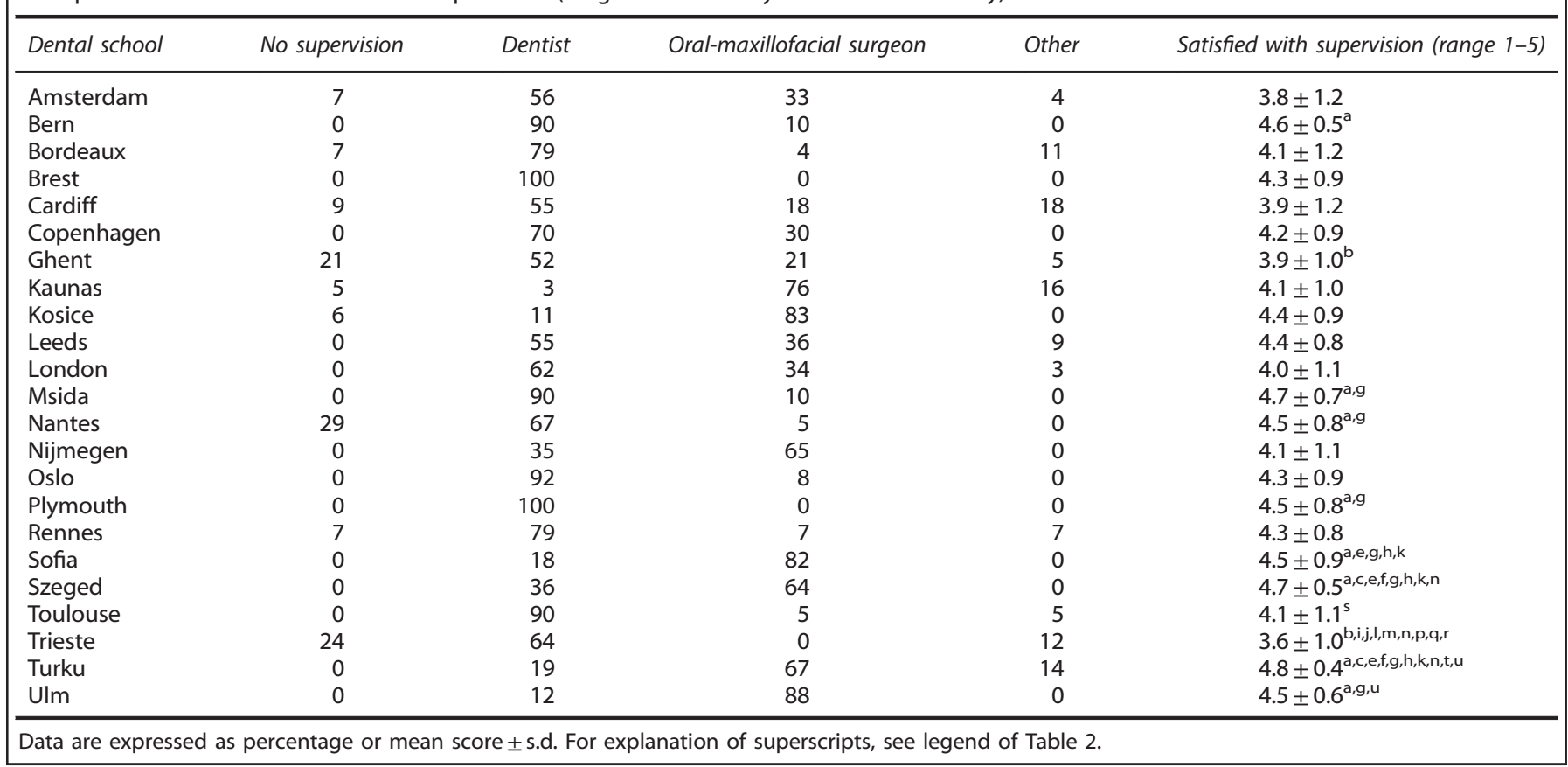

Table 5. Percentage of students from 23 different European dental schools who reported to have received education in specific extraction techniques

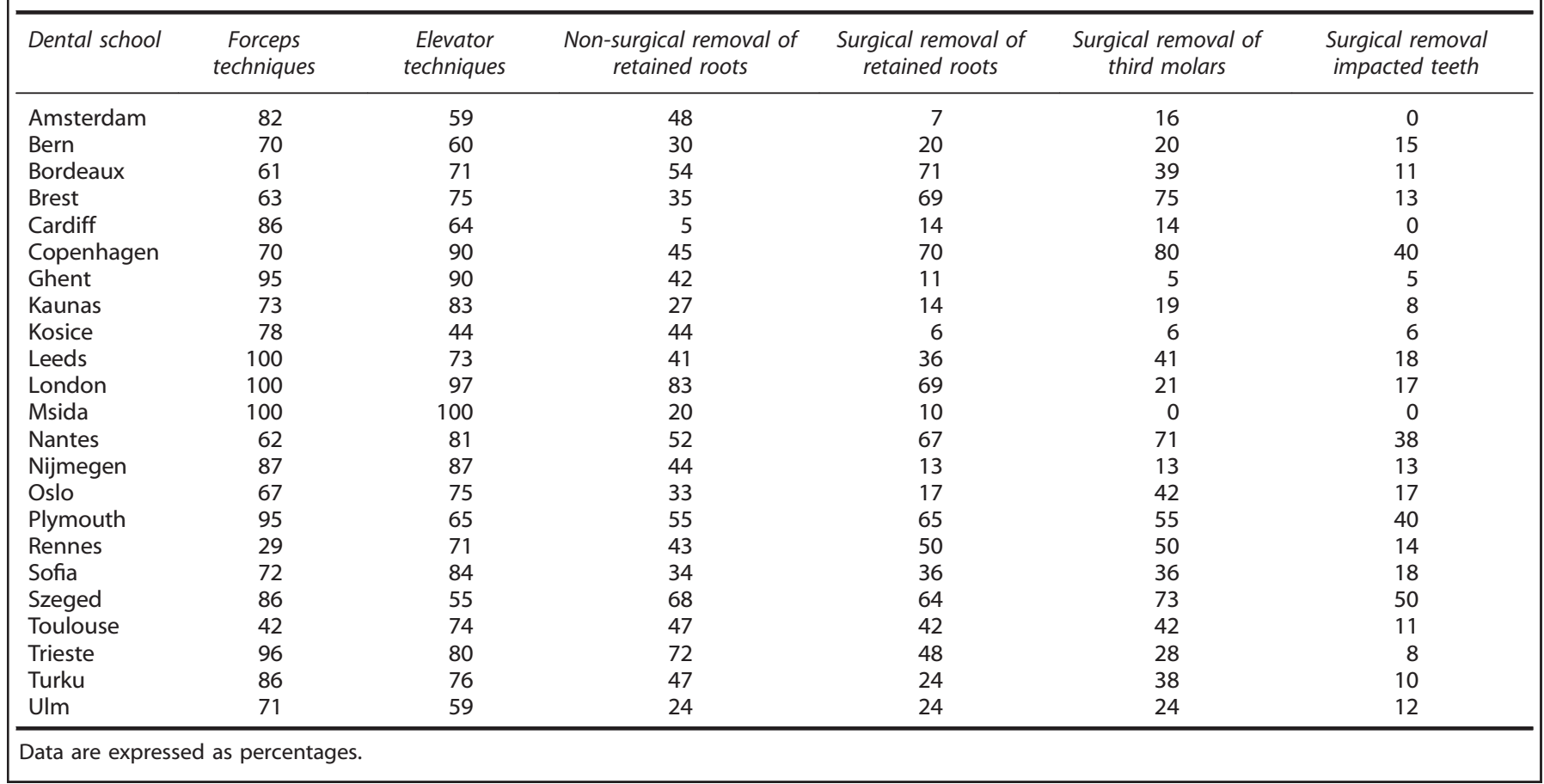

to study year (Table 1). The rating of the education at dental schools correlated negatively with the year of the initial teaching of the practical aspects of tooth extraction, indicating that an early clinical exposure is appreciated by the students.

Early exposure may also increase the number of extractions achieved by dental students during their clinical years. In 2008, the minimum number of extractions that undergraduates were expected to achieve during their clinical years varied between 11 dental schools in the UK from 20 to $115 .^{15}$ Shortage of suitable cases for undergraduates ${ }^{17}$ has been suggested to be one of the limits to develop confidence, ${ }^{6}$ as the number of surgical extractions performed increased competence. ${ }^{18}$ However, in another study, no significant relationship was observed between the total number of teeth extracted and the successful completion 
of the final assessment. ${ }^{5}$ Therefore, during recent years, setting numerical targets has increasingly been replaced in dental school curricula by a competency-based approach, although certain numerical targets are still present in most curricula. ${ }^{6}$

Knowledge of the relevant anatomy is important to perform a tooth extraction correctly. A few dental students in Europe felt

Table 6. The opinion of students from 23 different European dental schools whether they feel properly trained in tooth extraction and the overall rating of their extraction education (range $1=$ absolutely not to $5=$ absolutely)

\begin{tabular}{|c|c|c|}
\hline Dental school & Properly trained (range 1-5) & Overall rating (range 1-5) \\
\hline Amsterdam & $2.8 \pm 1.2$ & $2.5 \pm 1.0$ \\
\hline Bern & $3.6 \pm 0.7^{\mathrm{a}}$ & $4.0 \pm 0.8^{\mathrm{a}}$ \\
\hline Bordeaux & $3.6 \pm 0.8^{\mathrm{a}}$ & $3.8 \pm 0.7^{\mathrm{a}}$ \\
\hline Brest & $3.6 \pm 0.8$ & $4.0 \pm 0.8^{\mathrm{a}}$ \\
\hline Cardiff & $3.1 \pm 1.1^{c}$ & $2.9 \pm 1.0^{\mathrm{b}, \mathrm{c}, \mathrm{d}}$ \\
\hline Copenhagen & $4.1 \pm 0.7^{\mathrm{a}, \mathrm{b}, \mathrm{e}}$ & $4.3 \pm 0.7^{\mathrm{a}, c, e}$ \\
\hline Ghent & $2.7 \pm 1.1^{b, c, d, f f}$ & $3.0 \pm 0.9^{b, c, d, f}$ \\
\hline Kaunas & $3.1 \pm 1.0^{c, f}$ & $3.6 \pm 0.9^{\mathrm{a}, e, f, g}$ \\
\hline Kosice & $3.5 \pm 1.1$ & $3.7 \pm 0.9^{\mathrm{a}, \mathrm{e}, \mathrm{f}, \mathrm{g}}$ \\
\hline Leeds & $3.8 \pm 0.8^{\mathrm{a}, \mathrm{e}, \mathrm{g}, \mathrm{h}}$ & $4.1 \pm 0.8^{\mathrm{a}, \mathrm{e}, \mathrm{g}, \mathrm{h}}$ \\
\hline London & $3.9 \pm 0.9^{\mathrm{a}, \mathrm{e}, \mathrm{g}, \mathrm{h}}$ & $4.0 \pm 1.0^{\mathrm{a}, \mathrm{e}, \mathrm{g}}$ \\
\hline Msida & $3.4 \pm 0.7$ & $3.7 \pm 1.0^{\mathrm{a}}$ \\
\hline Nantes & $4.0 \pm 0.8^{\mathrm{a}, \mathrm{e}, \mathrm{g}, \mathrm{h}}$ & $4.1 \pm 0.8^{\mathrm{a}, \mathrm{e}, \mathrm{g}}$ \\
\hline Nijmegen & $3.3 \pm 1.0^{\mathrm{f}, \mathrm{k}, \mathrm{m}}$ & $3.3 \pm 1.0^{a, b, f, j, k, m}$ \\
\hline Oslo & $2.9 \pm 1.2^{\mathrm{f}, \mathrm{k}, \mathrm{m}}$ & $3.0 \pm 0.8^{\mathrm{b}, \mathrm{c}, \mathrm{d}, \mathrm{f}, \mathrm{j}, \mathrm{k}, \mathrm{m}}$ \\
\hline Plymouth & $4.3 \pm 0.8^{\mathrm{a}, \mathrm{b}, \mathrm{b}, \mathrm{c}, \mathrm{d}, \mathrm{e}, \mathrm{g}, \mathrm{h}, \mathrm{h}, \mathrm{j}, \mathrm{l}, \mathrm{l}, \mathrm{n}, \mathrm{o}}$ & $4.3 \pm 0.8^{\mathrm{a}, c, e, g, h, \mathrm{~h}, \mathrm{n}, \mathrm{o}}$ \\
\hline Rennes & $3.7 \pm 0.9^{9}$ & $3.8 \pm 0.9^{\mathrm{a}, \mathrm{e}, \mathrm{g}}$ \\
\hline Sofia & $4.0 \pm 0.7^{\mathrm{a}, \mathrm{e}, \mathrm{g}, \mathrm{h}, \mathrm{n}, \mathrm{o}}$ & $4.4 \pm 0.6^{\mathrm{a}, \mathrm{c}, \mathrm{e}, \mathrm{g}, \mathrm{h}, \mathrm{i}, \mathrm{l}, \mathrm{n}, \mathrm{o}}$ \\
\hline Szeged & $4.2 \pm 0.9^{\mathrm{a}, \mathrm{e}, \mathrm{g}, \mathrm{h}, \mathrm{n}, \mathrm{o}}$ & $4.5 \pm 0.8^{\mathrm{a}, \mathrm{c}, \mathrm{e}, \mathrm{e}, \mathrm{g}, \mathrm{h}, \mathrm{i}, \mathrm{n}, \mathrm{o}}$ \\
\hline Toulouse & $3.6 \pm 1.1^{9}$ & $3.6 \pm 0.8^{\mathrm{a}, \mathrm{e}, \mathrm{f}, \mathrm{p}, \mathrm{r}, \mathrm{s}}$ \\
\hline Trieste & $4.1+0.7^{\mathrm{a}, \mathrm{b}, \mathrm{e}, \mathrm{e}, \mathrm{h}, \mathrm{n}, \mathrm{n}, \mathrm{o}}$ & $4.1+0.7^{\mathrm{a}, \mathrm{e}, \mathrm{g}, \mathrm{n}, \mathrm{o}}$ \\
\hline Turku & $3.4 \pm 1.1^{p, s, u}$ & $4.1 \pm 1.1^{\mathrm{a}, \mathrm{e}, \mathrm{g}, \mathrm{n}, \mathrm{o}}$ \\
\hline Ulm & $2.2 \pm 1.1^{b, c, d, d, f, f, i, j, j, k, l, m, n, p, q, q, r, s, t, l}$ & $2.8 \pm 1.0^{\mathrm{b}, \mathrm{c}, \mathrm{d}, \mathrm{f}, \mathrm{h}, \mathrm{i}, \mathrm{i}, \mathrm{k}, \mathrm{k}, \mathrm{m}, \mathrm{p}, \mathrm{q}, \mathrm{r}, \mathrm{s}, \mathrm{t}, \mathrm{t}, \mathrm{r},}$ \\
\hline
\end{tabular}

Data are expressed as mean scores \pm s.d. For explanation of superscripts, see legend of Table 2 . insufficiently prepared with regard to anatomical aspects of extractions (Table 7). This is in line with a recent national survey of UK final year dental students, where $78 \%$ of the students reported that the anatomy teaching had been appropriate to their clinical needs. ${ }^{7}$ The percentage of students who feels insufficiently prepared for potential complications during a tooth extraction in a patient varied in the present study considerable between dental schools, from 0 to $60 \%$. We did not specify different types of potential complications in our questionnaire. In the UK, a high percentage of the final year dental students feel confident to manage haemorrhage. ${ }^{7,8}$ Therefore, it might be interesting to explore in future studies which (other) complications are anticipated by dental students in Europe.

Preclinical training on manikins may assist dental students to develop operative skills, may increase their level of competence and facilitate the transition to the clinic. ${ }^{19}$ In the UK, several dental school use preclinical models for the teaching of extraction skills. These models include commercially available models, virtual learning environments, pigs' heads and a rubber dam stretched over a cup. ${ }^{15,16,18}$ The present study shows that preclinical models are used at a considerable number of dental schools in Europe. At dental schools where a preclinical training model is widely used, the students considered it a useful preparation for the subsequent tooth extraction in a patient (Table 3). However, at two dental schools only few students found the preclinical training model useful. These differences in appreciation might be related to the type of preclinical model used and/or the amount of time to practice with it. Supervision during the use of the training model, as well as the amount of time between the training with the model and the transition to the clinic may also affect the opinion of the student. Further studies on the effectiveness of different types of preclinical training models for the teaching of extraction skills seem warranted.

Student feedback is an important component to monitor academic programs. Their input gives insight in teaching effectiveness and allows dental schools to identify possible weaknesses in their curriculum, which can result in improvement of clinical teaching. ${ }^{7,8}$ However, in the present study, the current

Table 7. Areas in which students from 23 different European dental schools felt insufficiently prepared before they performed their first tooth extraction in a patient

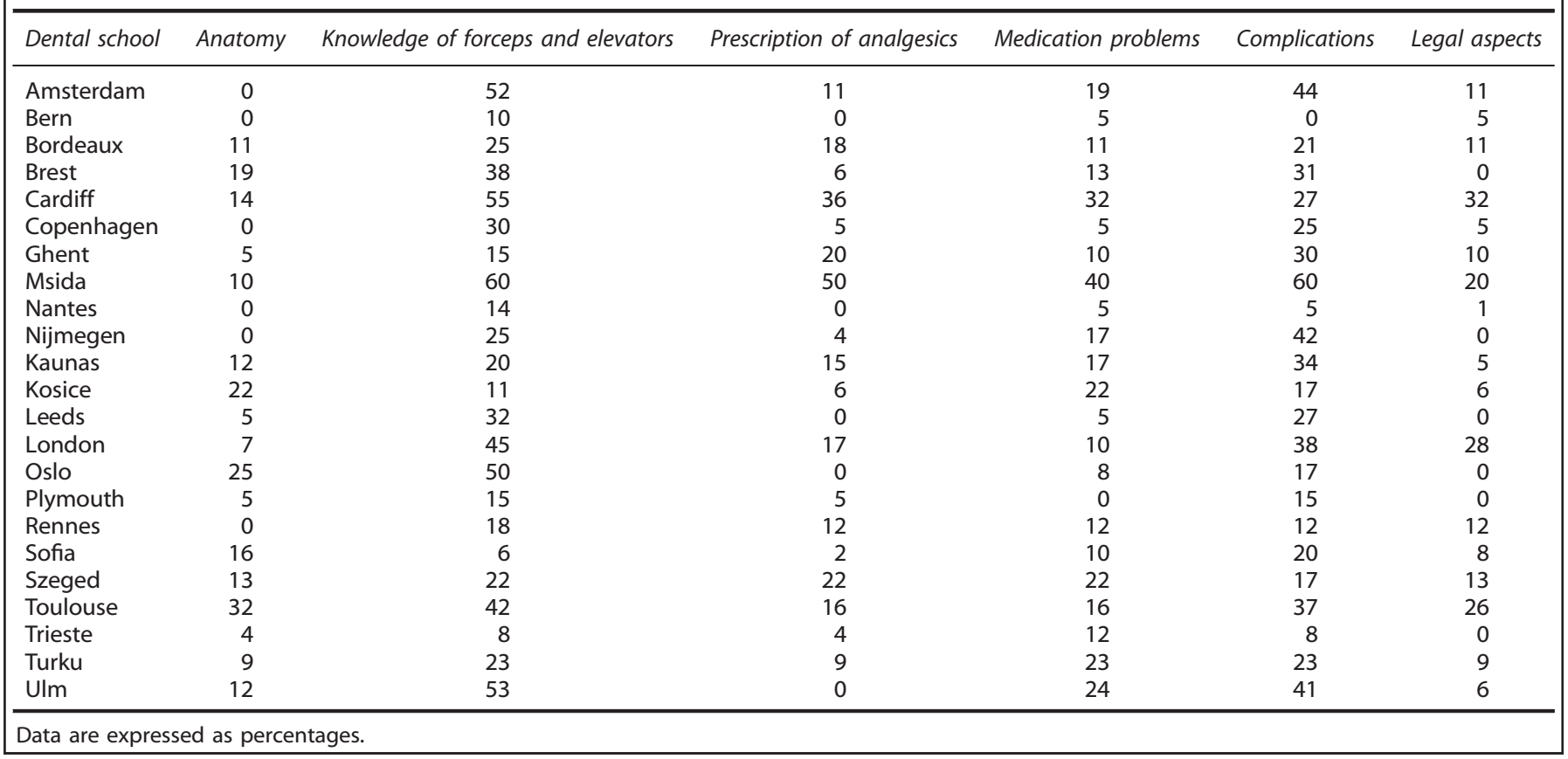


questionnaire was distributed through representatives of the European Dental Students Association. These students are more interested in education in general, ${ }^{20}$ which could have introduced a certain selection bias in the participating students. Another limitation of the type of web-based survey used in the present study is that a considerable amount of time may have passed between the moment that students received their training on tooth extraction and the moment they filled in the questionnaire, which could have affected the accuracy of the responses. In addition, the questionnaire was distributed to all European dental students in English. As this is not the native language of most students, this potentially could have resulted in misinterpretation of some questions. Finally, the question whether students feel properly trained in tooth extractions did not discriminate between their preparation to perform simple extractions and surgical extractions. Recently graduated dentists usually express the opinion that their dental school had given them sufficient knowledge to undertake simple forceps exodontia, but they feel much less prepared for surgical extractions. ${ }^{2-9}$ Considering the average study year of the respondents in the present study, several students may not have followed the complete study programme with regard to extractions at their dental school. As surgical extractions are taught at a later stage, this means that the expressed opinions of the European dental students will most rely on their experiences with forceps extractions.

Despite these limitations, this study supports previous studies which showed that European dental schools vary considerable in their curriculum. ${ }^{10-13}$ This variation in teaching programs could result in different level of competences of recently graduated dentists from different dental schools. ${ }^{6}$ Considering the international mobility of the contemporary dentists, a drive towards more convergence in dental education in Europe seems warranted. ${ }^{21}$

\section{ACKNOWLEDGEMENTS}

We thank K Ali, J Aps, B Bajkin, P Barkvoll, S Camilleri, JA Carey, A Hemprich, S Janner, E Jilsink, P Koopman, P Limbour, M Maglione, K Nagy, S Osailan, EM Pinholt, A Schurr, $V$ Sivarajasingam, $T$ Teerijoki-Oksa and $M$ Wipf for their assistance in the distribution of the questionnaire.

\section{COMPETING INTERESTS}

The authors declare no conflict of interest.

\section{REFERENCES}

1 Cowpe J, Plasschaert A, Harzer W, Vinkka-Puhakka H, Walmsley AD. Profile and competences for the graduating European dentist-update 2009. Eur J Dent EduC 2010; 14: 193-202.

2 Murray FJ, Blinkhorn AS, Bulman J. An assessment of the views held by recent graduates on their undergraduate course. Eur J Dent Educ 1999; 3: 3-9.

3 Bartlett DW, Coward PY, Wilson R, Goodsman D, Darby J. Vocational training experiences and perceptions of vocational training reported by the 1999 cohort of vocational dental practitioners and their trainers in England and Wales. Br Dent J 2001; 191: 265-270.
4 Patel J, Fox K, Grieveson B, Youngson CC. Undergraduate training as preparation for vocational training in England: a survey of vocational dental practitioners' and their trainers' views. Br Dent J 2006; 201: 9-15.

5 Durham JA, Moore UJ, Corbett IP, Thomson PJ. Assessing competency in dentoalveolar surgery: a 3-year study of cumulative experience in the undergraduate curriculum. Eur J Dent Educ 2007; 11: 200-207.

6 Honey J, Lynch CD, Burke FM, Gilmour AS. Ready for practice? A study of confidence levels of final year dental students at Cardiff University and University College Cork. Eur J Dent Educ 2011; 15: 98-103.

7 Macluskey M, Durham J, Bell A, Cowpe J, Crean SJ, Dargue A et al. A national survey of UK final year students' opinion of undergraduate oral surgery teaching. Eur J Dent Educ 2012; 16: e205-e212.

8 Maclusky M, Sheperd S, Carter E, Bulsara Y, Durham JA, Bell A et al. A national follow-up survey of UK graduates opinion of undergraduate oral surgery teaching. Eur J Dent Educ 2015, e-pub ahead of print 29 January 2015; doi: 10.1111/eje.12158.

9 Yiu CKY, McGrath C, Bridges S, Corbet EF, Botelho MG, Dyson JE et al. Self-perceived preparedness for dental practice amongst graduates of The University of Hong Kong's integrated PBL dental curriculum. Eur J Dent Educ 2012 16: e96-e105.

10 Brand HS, Tan LLS, van der Spek SJ, Baart JA. European dental students' opinions on their local anaesthesia education. Eur J Dent Educ 2011; 15: 47-52.

11 Brand HS, Kuin D, Baart JA. A survey of local anaesthesia education in European dental schools. Eur J Dent Educ 2008; 12: 85-88; DOI: 10.1111/ j.1600-0579.2008.00505.x

12 Dozic A, Kharbanda AK, Kamell H, Brand HS. European dental students' opinions about visual and digital tooth color determination systems. J Dent 2011; 39: e23-e28.

13 Brand HS, Kamell H, Kharbanda A, Dozic A. Students' perceptions of materials and techniques used at European dental schools in the education of fixed prosthodoctics. J Dent Educ 2013; 77: 1140-1146.

14 Roelofsma PHMP, Bottema CW, Smeets JEM. Examine: A Web Survey Tool for Research Design and Analysis. SLA Press: Amsterdam, The Netherlands, 2005.

15 Macluskey M, Durham J. Oral surgery undergraduate teaching and experience in the United Kingdom: a national survey. Eur J Dent Educ 2008; 13: 52-57.

16 Ali K, McCarthy A, Robbins J, Hefferman E, Coombes L. Management of impacted wisdom teeth: teaching of undergraduate students in UK dental schools. Eur $J$ Dent Educ 2014; 18: 135-141.

17 Durham J, Balmer C, Bell A, Cowan G, Cowpe J, Crean SJ et al. A generic consensus assessment of undergraduate competence in forceps exodontia in the United Kingdom. Eur J Dent Educ 2010; 14: 210-214.

18 Moore U, Durham J, Corbett I, Thomson P. The influence of staffing and timetabling on achieving competence in surgical extractions. Eur $J$ Dent Educ 2009; 13: 15-19.

19 Stelzle F, Farhoumand D, Neukam FW, Nkenke E. Implementation and validation of an extraction course using mannequin models for undergraduate dental students. Acta Odontol Scand 2011; 69: 80-87.

20 Divaris K, Barlow PJ, Chendea SA. The academic environment: the student's perspective. Eur J Dent Educ 2008; 12: 120-130.

21 Scott J. Dental education in Europe; the challenge of variety. J Dent Educ 2003; 67: $69-78$.

\footnotetext{
(c) (i) This work is licensed under a Creative Commons Attribution 4.0 International License. The images or other third party material in this article are included in the article's Creative Commons license, unless indicated otherwise in the credit line; if the material is not included under the Creative Commons license, users will need to obtain permission from the license holder to reproduce the material. To view a copy of this license, visit http://creativecommons.org/licenses/ by/4.0/
} 